\title{
Anticoagulation Therapy for Venous Thromboembolism in the Real World - From the COMMAND VTE Registry -
}

\author{
Yugo Yamashita, MD; Takeshi Morimoto, MD; Hidewo Amano, MD; Toru Takase, MD; \\ Seiichi Hiramori, MD; Kitae Kim, MD; Takashi Konishi, MD; Masaharu Akao, MD; \\ Yohei Kobayashi, MD; Takeshi Inoue, MD; Maki Oi, MD; Toshiaki Izumi, MD; \\ Kotaro Takahashi, MD; Tomohisa Tada, MD; Po-Min Chen, MD; Koichiro Murata, MD; \\ Yoshiaki Tsuyuki, MD; Hiroshi Sakai, MD; Syunsuke Saga, MD; Tomoki Sasa, MD; \\ Jiro Sakamoto, MD; Chinatsu Yamada, MD; Minako Kinoshita, MD; Kiyonori Togi, MD; \\ Tomoyuki Ikeda, MD; Katsuhisa Ishii, MD; Kazuhisa Kaneda, MD; Hiroshi Mabuchi, MD; \\ Hideo Otani, MD; Kensuke Takabayashi, MD; Mamoru Takahashi, MD; Hiroki Shiomi, MD; \\ Takeru Makiyama, MD; Koh Ono, MD; Takeshi Kimura, MD \\ on behalf of COMMAND VTE Registry Investigators
}

\begin{abstract}
Background: Venous thromboembolism (VTE) has a long-term risk of recurrence, which can be prevented by anticoagulation therapy.
Methods and Results: The COMMAND VTE Registry is a multicenter registry enrolling 3,027 consecutive patients with acute symptomatic VTE between January 2010 and August 2014. The entire cohort was divided into the transient risk ( $n=855,28 \%$ ), unprovoked $(n=1,477,49 \%)$, and cancer groups $(n=695,23 \%)$. The rate of anticoagulation discontinuation was highest in the cancer group (transient risk: $37.3 \%$ vs. unprovoked: $21.4 \%$ vs. cancer: $43.5 \%$ at 1 year, $\mathrm{P}<0.001$ ). The cumulative 5 -year incidences of recurrent VTE, major bleeding and all-cause death were highest in the cancer group (recurrent VTE: $7.9 \%$ vs. 9.3\% vs. 17.7\%, $\mathrm{P}<0.001$; major bleeding: $9.0 \%$ vs. $9.4 \%$ vs. $26.6 \%, \mathrm{P}<0.001$; and all-cause death: $17.4 \%$ vs. $15.3 \%$ vs. $73.1 \%, \mathrm{P}<0.001$ ). After discontinuation of anticoagulation therapy, the cumulative 3-year incidence of recurrent VTE was lowest in the transient risk group (transient risk: $6.1 \%$ vs. unprovoked: $15.3 \%$ vs. cancer: $13.2 \%, \mathrm{P}=0.001$ ). The cumulative 3 -year incidence of recurrent VTE beyond 1 year was lower in patients on anticoagulation than in patients off anticoagulation at 1 year in the unprovoked group (on: $3.7 \%$ vs. off: $12.2 \%, P<0.001$ ), but not in the transient risk and cancer groups (respectively, $1.6 \%$ vs. $2.5 \%, P=0.30 ; 5.6 \%$ vs. $8.6 \%, P=0.44$ ).
\end{abstract}

Conclusions: The duration of anticoagulation therapy varied widely in discordance with current guideline recommendations. Optimal duration of anticoagulation therapy should be defined according to the risk of recurrent VTE and bleeding as well as death.

Key Words: Anticoagulants; Bleeding; Mortality; Recurrence; Venous thromboembolism

V enous thromboembolism (VTE), including pulmonary embolism (PE) and deep vein thrombosis (DVT), is a major health problem in the world, and the third most frequent cardiovascular disease in Western countries. ${ }^{1}$ VTE has a long-term risk of recurrence, which can be prevented by anticoagulation therapy. ${ }^{2}$ The current guidelines recommend specific durations of anticoagulation therapy for the prevention of recurrent VTE depending on the presence or absence of a transient risk factor for VTE, previous VTE, and active cancer. ${ }^{36}$ However, previous

Received October 12, 2017; revised manuscript received December 3, 2017; accepted December 21, 2017; released online March 23, 2018 Time for primary review: 48 days

Department of Cardiovascular Medicine, Graduate School of Medicine, Kyoto University, Kyoto (Y.Y., H. Shiomi, T. Makiyama, K.O., T. Kimura); Department of Clinical Epidemiology, Hyogo College of Medicine, Nishinomiya (T. Morimoto); Department of Cardiovascular Medicine, Kurashiki Central Hospital, Kurashiki (H.A.); Department of Cardiology, Kindai University Hospital, Osaka (T. Takase); Department of Cardiology, Kokura Memorial Hospital, Kokura (S.H.); Department of Cardiovascular Medicine, Kobe City Medical Center General Hospital, Kobe (K. Kim); Department of Cardiology, Japanese Red Cross Otsu Hospital, Otsu (T. Konishi); Department of Cardiology, National Hospital Organization Kyoto Medical Center, Kyoto (M.A.); Department of Cardiovascular Center, Osaka Red Cross Hospital, Osaka (Y.K.); Department of Cardiology, Shiga Medical Center for Adults, Moriyama (T. Inoue); Department of Cardiology, Japanese Red Cross Wakayama Medical Center, Wakayama (M.O.); Cardiovascular Center, The Tazuke Kofukai Medical Research Institute, Kitano Hospital, Osaka (T. Izumi); Department of Cardiology, Shizuoka General Hospital, Shizuoka (K.T., T. Tada); Department of Cardiology, Osaka Saiseikai Noe Hospital, Osaka (P.-M.C.); Department of Cardiology, Shizuoka City Shizuoka Hospital, Shizuoka (K.M.); (Footnote continued the next page.) 
clinical trials investigating the optimal management strategies for VTE were not specifically designed to address the optimal duration of anticoagulation therapy. ${ }^{7-9}$ There is still uncertainty about the optimal duration of anticoagulation therapy, leading to widely varying durations of anticoagulation therapy in daily clinical practice.

Data on current real-world management strategies and long-term outcomes of patients with VTE are important for understanding the current issues and unmet needs of optimal management of VTE. However, most of the data on patients with VTE have come from randomized clinical trials with strict inclusion and exclusion criteria. In fact, it was reported that almost one-quarter of patients with VTE have at least 1 exclusion criterion making them ineligible for randomized clinical trials. ${ }^{\mathbf{1 0}}$ Furthermore, there is a scarcity of data on current real-world management strategies and long-term outcomes of patients with VTE in Asia, including Japan. A previous report from Japan suggested that the management strategies in the acute phase were different from those in other Western countries. ${ }^{11}$ Therefore, we sought to evaluate the clinical characteristics, management strategies, and long-term outcomes of consecutive patients with acute symptomatic VTE in the real world.

\section{Methods}

\section{Study Population}

The COMMAND VTE (COntemporary ManageMent AND outcomes in patients with Venous ThromboEmbolism) Registry is a physician-initiated, retrospective, multicenter cohort study enrolling consecutive patients with acute symptomatic VTE objectively confirmed by imaging examination (ultrasound, contrast-enhanced computed tomography, ventilation-perfusion lung scintigraphy, pulmonary angiography, or contrast venography) or by autopsy among 29 centers in Japan between January 2010 and August 2014 before the introduction of direct oral anticoagulants (DOAC) for VTE in Japan.

We searched the hospital databases for clinical diagnosis and imaging examinations, and enrolled consecutive patients who met the definition of acute symptomatic VTE diagnosed within 31 days from symptom onset during the study period. ${ }^{12}$ The symptoms of VTE were defined as follows: sudden onset dyspnea, pleuritic chest pain, substernal chest pain, cough, fever, hemoptysis, and syncope for PE; and erythema, warmth, pain, swelling, tenderness, and pain upon dorsiflexion of the foot for DVT. ${ }^{13,14}$ Additionally, sudden onset abnormalities in vital signs such as a decrease in arterial oxygen saturation and hypotension were also regarded as symptoms of PE. The presence or absence of symptoms was evaluated at the time of the imaging studies. The relevant review board or ethics committee in all 29 participating centers (Appendix S1) approved the research protocol. Written informed consent from each patient was waived because we used clinical information obtained in routine clinical practice and none of the patients refused to participate in the study when contacted for follow-up. This method is concordant with the guidelines for epidemiological studies issued by the Ministry of Health, Labor, and Welfare in Japan.

A total of 3,027 consecutive patients with acute symptomatic VTE were enrolled in the registry after screening of 19,634 consecutive patients with suspected VTE for eligibility through chart review by the physicians at each institution. In this primary report from the COMMAND VTE Registry, the entire cohort was divided into 3 groups according to the American Heart Association (AHA) and American College of Chest Physicians guideline recommendations for the duration of anticoagulation therapy: the transient risk, unprovoked, and cancer groups (Figure 1)..$^{\mathbf{4 , 5}}$ First, patients with associated active cancer were classified into the cancer group. Second, among the patients without active cancer, those without a transient risk factor for VTE or with previous VTE were classified into the unprovoked group. Finally, patients with a transient risk factor for VTE were classified as the transient risk group. We compared the clinical characteristics, management strategies and long-term outcomes among the 3 groups with a median follow-up period of 1,218 (interquartile range [IQR]: 847-1,764) days for surviving patients $(95.1 \%$ followup rate at 1 year).

Data Collection and Definitions of Patients' Characteristics Data for the patients' characteristics were collected from hospital charts or hospital databases according to the prespecified definitions, using an electronic case report form in a web-based database system. The physicians at each institution were responsible for data entry, and data were automatically checked for missing or contradictory input and values out of the expected range. Additional editing checks were performed at the general office of the registry.

Transient risk factors for VTE included recent surgery (within 2 months prior to VTE), recent immobilization (defined as non-surgical bed-ridden patients with bathroom privileges for $>4$ days within 2 months prior to VTE), longdistance travel (travel lasting $\geq 6 \mathrm{~h}$ in the previous 3 weeks), central venous catheter use, pregnancy or puerperium, recent leg trauma, fracture or burn (any events requiring immobilization in the past 2 months), severe infection, and estrogen use. ${ }^{15}$ Patients with active cancer were defined as

Division of Cardiology, Shimada Municipal Hospital, Shimada (Y.T.); Department of Cardiovascular and Respiratory Medicine, Shiga University of Medical Science, Otsu (H. Sakai); Department of Cardiology, Hyogo Prefectural Amagasaki General Medical Center, Amagasaki (S.S.); Department of Cardiology, Kishiwada City Hospital, Kishiwada (T.S.); Department of Cardiology, Tenri Hospital, Tenri (J.S.); Department of Cardiovascular Medicine, Kyoto Okamoto Memorial Hospital, Kyoto (C.Y.); Department of Cardiology, Nishikobe Medical Center, Kobe (M.K.); Division of Cardiology, Nara Hospital, Kindai University Faculty of Medicine, Ikoma (K. Togi); Department of Cardiology, Hikone Municipal Hospital, Hikone (T. Ikeda); Department of Cardiology, Kansai Electric Power Hospital, Osaka (K.I.); Department of Cardiology, Mitsubishi Kyoto Hospital, Kyoto (K. Kaneda); Department of Cardiology, Koto Memorial Hospital, Higashiomi (H.M.); Department of Cardiovascular Medicine, Sugita Genpaku Memorial Obama Municipal Hospital, Obama (H.O.); Department of Cardiology, Hirakata Kohsai Hospital, Hirakata (K. Takabayashi); and Department of Cardiology, Shimabara Hospital, Kyoto (M.T.), Japan

This paper was presented at the $82^{\text {nd }}$ Annual Scientific Meeting of the Japanese Circulation Society, Late Breaking Cohort Studies 1-6 (March 23, 2018, Osaka, Japan).

Mailing address: Takeshi Kimura, MD, Department of Cardiovascular Medicine, Graduate School of Medicine, Kyoto University, 54 Shogoin Kawahara-cho, Sakyo-ku, Kyoto 606-8507, Japan. E-mail: taketaka@kuhp.kyoto-u.ac.jp

ISSN-1346-9843 All rights are reserved to the Japanese Circulation Society. For permissions, please e-mail: cj@j-circ.or.jp 


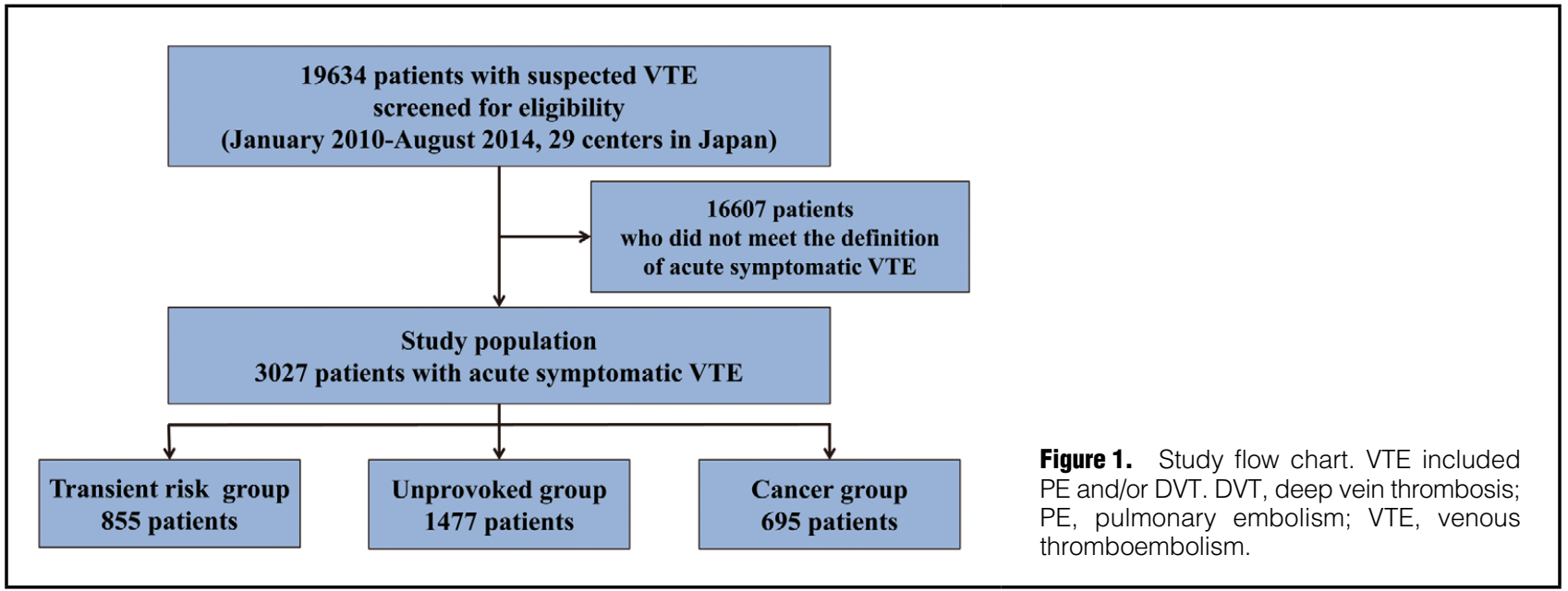

those on treatment for cancer, such as chemotherapy or radiotherapy, those scheduled to undergo cancer surgery, those with metastasis to other organs, and/or those with terminal cancer (expected life expectancy $\leq 6$ months) at the time of the diagnosis. Initial anticoagulation therapy was defined as parenteral anticoagulation therapy in the acute phase (unfractionated heparin or fondaparinux) for $\leq 10$ days after the diagnosis, whereas anticoagulation therapy beyond the acute phase was defined as anticoagulation therapy (warfarin, DOAC, or unfractionated heparin) that was continued beyond 10 days after the diagnosis. The detailed definitions of other patient characteristics are described in Appendix S2.

\section{Clinical Follow-up and Endpoints}

Collection of follow-up information was mainly conducted through review of hospital charts, and additional follow-up information was collected through contact with patients, relatives, and/or referring physicians by phone and/or mail with questions regarding vital status, recurrent VTE, bleeding, invasive procedure, acute myocardial infarction, stroke and status of anticoagulation therapy. In this retrospective cohort study, data collection for follow-up events was performed between July 2016 and March 2017.

The primary outcome measure was recurrent VTE, which was defined as PE and/or DVT with symptoms accompanied by confirmation of new thrombus or exacerbation of the thrombus by objective imaging examinations or autopsy. ${ }^{\mathbf{1 6}}$ The secondary outcome measures were major bleeding and all-cause death. Major bleeding was defined as International Society of Thrombosis and Hemostasis (ISTH) major bleeding, which consisted of a reduction in the hemoglobin level by at least $2 \mathrm{~g} / \mathrm{dL}$, transfusion of at least 2 units of blood or symptomatic bleeding in a critical area or organ. ${ }^{17}$ The independent clinical event committee (Appendix S3), which was unaware of the patients' characteristics, reviewed all study outcomes, and classified the causes of deaths as PE, cardiac event, cancer, bleeding event, other non-cardiac event, or unknown cause. ${ }^{\mathbf{1 8}}$ The definitions of other clinical events are described in Appendix S2.

Anticoagulation therapy cessation was classified as discontinuation or interruption according to prespecified definitions. Discontinuation of anticoagulation was defined as withdrawal of anticoagulation therapy lasting $>14$ days for any reason, such as physician's judgment in the absence of adverse events, bleeding event, drug side effect, and nonadherence of the patient. Interruption of anticoagulation was defined as temporary cessation of anticoagulation therapy with reinstitution within 14 days for any reason, including invasive procedure and bleeding events, etc. Scheduled switch from one anticoagulation therapy to another was not regarded as interruption of anticoagulation. Data for international normalized ratio (INR) during follow-up in patients receiving warfarin were collected from the hospital charts of the centers where the index VTE was diagnosed. Time in therapeutic range (TTR) was calculated by the Rosendaal method, ${ }^{19}$ according to a therapeutic INR range of 1.5-2.5, which is recommended in the Japanese guidelines, ${ }^{6}$ as well as a therapeutic INR range of 2.0-3.0, which is recommended in the Western guidelines. ${ }^{3-5}$

\section{Statistical Analysis}

Categorical variables are presented as numbers and percentages. Continuous variables are presented as the mean and standard deviation or the median and IQR based on their distributions. Categorical variables were compared with the chi-square test. Continuous variables were compared using one-way analysis of variance or KruskalWallis test based on their distributions. We used the Kaplan-Meier method to estimate the cumulative incidence and assessed the differences with a log-rank test. We used a Cox proportional hazard model to estimate the hazard ratio (HR) and 95\% confidence intervals (CI) for the risk of the unprovoked group and cancer group, respectively, relative to transient risk group for the clinical outcomes. As a sensitivity analysis, we used Fine and Gray's method to estimate the $\mathrm{HR}$ and $95 \%$ CIs, taking into account the competing risk of all-cause death. ${ }^{20} \mathrm{We}$ also compared the incidence for recurrent VTE after discontinuation of anticoagulation therapy across the 3 groups. Eligible patients for this analysis were those who received anticoagulation therapy beyond the acute phase, and were free from recurrent VTE before discontinuation. Furthermore, to examine the effect of anticoagulation therapy beyond 1 year on recurrent VTE, a landmark analysis based on the status of anticoagulation at 1 year was conducted. We compared the cumulative incidences for recurrent VTE beyond 1 year between the 2 groups of patients on and off anticoagulation at the 1-year landmark point. All statistical analyses were conducted by a physician (Y.Y.) and a statistician 
(T. Morimoto) with the use of JMP version 10.0.2 (SAS Institute Inc., Cary, NC, USA) or SAS 9.4 (SAS Institute Inc.). All reported $\mathrm{P}$-values were 2-tailed, and $\mathrm{P}<0.05$ was considered statistically significant.

\section{Results}

\section{Patients' Characteristics}

In the entire study population, the mean age was $67.2 \pm 15.3$ years, $61 \%$ was female, and body weight and body mass index were $57.9 \pm 13.7 \mathrm{~kg}$ and $23.2 \pm 4.4 \mathrm{~kg} / \mathrm{m}^{2}$, respectively. The transient risk, unprovoked, and cancer groups comprised 855 patients $(28 \%), 1,477$ patients $(49 \%)$, and 695 patients $(23 \%)$, respectively. The proportions of PE with and without DVT at presentation were not significantly different among the 3 groups, although baseline characteristics were different across the 3 groups in several aspects (Table 1). Initial anticoagulation therapy was administered most frequently in the transient risk group (Table 1), while anticoagulation therapy beyond the acute phase was implemented least frequently in the cancer group (Table 2). Median TTR for warfarin users according to Japanese guideline recommendations (therapeutic INR range of 1.52.5) was lowest in the cancer group (Table 2). The types of cancer in the cancer group are shown in Table S1.

\section{Clinical Outcomes and Management Strategies of Anticoagulation Therapy}

The cumulative 5-year incidence of recurrent VTE was highest in the cancer group (transient risk: $7.9 \%$ vs.

\begin{tabular}{|c|c|c|c|c|c|}
\hline & $\begin{array}{c}\text { Total } \\
(n=3,027)\end{array}$ & $\begin{array}{l}\text { Transient risk } \\
(\mathrm{n}=855)\end{array}$ & $\begin{array}{l}\text { Unprovoked } \\
(n=1,477)\end{array}$ & $\begin{array}{l}\text { Cancer } \\
(\mathrm{n}=695)\end{array}$ & $P$ value \\
\hline \multicolumn{6}{|l|}{ Baseline characteristics } \\
\hline Age (years) & $67.2 \pm 15.3$ & $65.7 \pm 18.0$ & $68.3 \pm 14.9$ & $66.5 \pm 12.2$ & $<0.001$ \\
\hline Female sex & $1,858(61 \%)$ & $605(71 \%)$ & $839(57 \%)$ & $414(60 \%)$ & $<0.001$ \\
\hline Body weight $(\mathrm{kg})$ & $57.9 \pm 13.7$ & $57.8 \pm 14.5$ & $59.2 \pm 13.8$ & $55.3 \pm 12.3$ & $<0.001$ \\
\hline Body mass index $\left(\mathrm{kg} / \mathrm{m}^{2}\right)$ & $23.2 \pm 4.4$ & $23.5 \pm 4.8$ & $23.6 \pm 4.3$ & $22.1 \pm 4.0$ & $<0.001$ \\
\hline Body mass index $\geq 30 \mathrm{~kg} / \mathrm{m}^{2}$ & $169(5.6 \%)$ & $61(7.1 \%)$ & $82(5.6 \%)$ & $26(3.7 \%)$ & 0.02 \\
\hline Hypertension & $1,161(38 \%)$ & $328(38 \%)$ & $631(43 \%)$ & $202(29 \%)$ & $<0.001$ \\
\hline Diabetes mellitus & $386(13 \%)$ & $109(13 \%)$ & $189(13 \%)$ & $88(13 \%)$ & 0.99 \\
\hline Dyslipidemia & $608(20 \%)$ & $158(18 \%)$ & $353(24 \%)$ & 97 (14\%) & $<0.001$ \\
\hline Chronic kidney disease & $572(19 \%)$ & $131(15 \%)$ & $324(22 \%)$ & $117(17 \%)$ & $<0.001$ \\
\hline Dialysis & $21(0.7 \%)$ & $9(1.1 \%)$ & $7(0.5 \%)$ & $5(0.7 \%)$ & 0.27 \\
\hline Chronic lung disease & $271(9.0 \%)$ & $62(7.3 \%)$ & $153(10.4 \%)$ & $56(8.1 \%)$ & 0.03 \\
\hline Previous heart failure & $101(3.3 \%)$ & $39(4.6 \%)$ & $52(3.5 \%)$ & $10(1.4 \%)$ & 0.003 \\
\hline Previous MI & $53(1.8 \%)$ & $21(2.5 \%)$ & $26(1.8 \%)$ & $6(0.9 \%)$ & 0.06 \\
\hline Previous stroke & $270(8.9 \%)$ & $108(12.6 \%)$ & $126(8.5 \%)$ & $36(5.2 \%)$ & $<0.001$ \\
\hline Atrial fibrillation & $129(4.2 \%)$ & $46(5.4 \%)$ & $59(4.0 \%)$ & $24(3.5 \%)$ & 0.14 \\
\hline Liver cirrhosis & $26(0.9 \%)$ & $9(1.1 \%)$ & $9(0.6 \%)$ & $8(1.2 \%)$ & 0.34 \\
\hline Connective tissue disease & $244(8.1 \%)$ & 59 (6.9\%) & $164(11.1 \%)$ & $21(3.0 \%)$ & $<0.001$ \\
\hline Previous VTE & $178(5.9 \%)$ & $0(0.0 \%)$ & $138(9.3 \%)$ & $40(5.8 \%)$ & $<0.001$ \\
\hline Previous major bleeding & $231(7.6 \%)$ & $92(10.8 \%)$ & $67(4.5 \%)$ & $72(10.4 \%)$ & $<0.001$ \\
\hline \multicolumn{6}{|l|}{ Presentation } \\
\hline PE with or without DVT & $1,715(57 \%)$ & $463(54 \%)$ & $859(58 \%)$ & $393(57 \%)$ & 0.17 \\
\hline Hypoxemia & $850 / 1,715$ (50\%) & $254 / 463(55 \%)$ & $435 / 859(51 \%)$ & $161 / 393(41 \%)$ & $<0.001$ \\
\hline Shock & $179 / 1,715$ (10.4\%) & $67 / 463(14.5 \%)$ & $87 / 859(10.1 \%)$ & 25/393 (6.4\%) & $<0.001$ \\
\hline Cardiac arrest/collapse & $80 / 1,715(4.7 \%)$ & $33 / 463(7.1 \%)$ & $40 / 859(4.7 \%)$ & $7 / 393(1.8 \%)$ & 0.001 \\
\hline DVT only & $1,312(43 \%)$ & $392(46 \%)$ & $618(42 \%)$ & $302(43 \%)$ & 0.17 \\
\hline Proximal DVT & $921 / 1,312(70 \%)$ & 264/392 (67\%) & $440 / 618(71 \%)$ & $217 / 302(72 \%)$ & 0.33 \\
\hline \multicolumn{6}{|l|}{ Laboratory testing at diagnosis } \\
\hline $\begin{array}{l}\text { Anemia (hemoglobin }<11.0 \mathrm{~g} / \mathrm{dL}) \\
(\mathrm{n}=3,012)\end{array}$ & $1,012 / 3,012(34 \%)$ & $339 / 850(40 \%)$ & $298 / 1,469(20 \%)$ & $375 / 693(54 \%)$ & $<0.001$ \\
\hline $\begin{array}{l}\text { Thrombocytopenia } \\
\left.\text { (platelets }<100 \times 10^{9} / L\right)(n=3,012)\end{array}$ & $164 / 3,012(5.4 \%)$ & $31 / 850(3.6 \%)$ & $79 / 1,469(5.4 \%)$ & $54 / 693(7.8 \%)$ & 0.002 \\
\hline eGFR $\left(\mathrm{mL} / \mathrm{min} / 1.73 \mathrm{~m}^{2}\right)(\mathrm{n}=3,001)$ & $70.5 \pm 30.4$ & $76.5 \pm 33.6$ & $65.6 \pm 27.4$ & $73.2 \pm 30.5$ & $<0.001$ \\
\hline D-dimer $(\mu \mathrm{g} / \mathrm{mL})(\mathrm{n}=2,852)$ & $10.2(5.0-20.4)$ & $12.1(5.9-23.6)$ & $8.9(4.4-16.9)$ & $13.3(6.2-25.5)$ & $<0.001$ \\
\hline \multicolumn{6}{|l|}{ Thrombophilia } \\
\hline Patients tested & $1,361(45 \%)$ & $363(42 \%)$ & $812(55 \%)$ & $186(27 \%)$ & $<0.001$ \\
\hline Protein $\mathrm{C}$ deficiency & $58(1.9 \%)$ & $11(1.3 \%)$ & $37(2.5 \%)$ & $10(1.4 \%)$ & 0.07 \\
\hline Protein S deficiency & $65(2.2 \%)$ & $26(3.0 \%)$ & $33(2.2 \%)$ & $6(0.9 \%)$ & 0.006 \\
\hline Antithrombin deficiency & $22(0.7 \%)$ & $4(0.5 \%)$ & $14(1.0 \%)$ & $4(0.6 \%)$ & 0.37 \\
\hline Antiphospholipid antibody & $11(0.4 \%)$ & $1(0.1 \%)$ & $10(0.7 \%)$ & $0(0.0 \%)$ & 0.02 \\
\hline
\end{tabular}




\begin{tabular}{|c|c|c|c|c|c|}
\hline & $\begin{array}{c}\text { Total } \\
(n=3,027)\end{array}$ & $\begin{array}{c}\text { Transient risk } \\
(\mathrm{n}=855)\end{array}$ & $\begin{array}{c}\text { Unprovoked } \\
(n=1,477)\end{array}$ & $\begin{array}{l}\text { Cancer } \\
(n=695)\end{array}$ & $P$ value \\
\hline \multicolumn{6}{|l|}{ Treatment in the acute phase } \\
\hline Initial anticoagulation therapy & $2,534(84 \%)$ & $751(88 \%)$ & $1,206(82 \%)$ & $577(83 \%)$ & $<0.001$ \\
\hline Unfractionated heparin & $2,417(80 \%)$ & $722(84 \%)$ & $1,145(78 \%)$ & $550(79 \%)$ & $<0.001$ \\
\hline Fondaparinux & $168(5.6 \%)$ & $44(5.2 \%)$ & $86(5.8 \%)$ & $38(5.5 \%)$ & 0.78 \\
\hline Thrombolysis & $430(14.2 \%)$ & $107(12.5 \%)$ & $270(18.3 \%)$ & $53(7.6 \%)$ & $<0.001$ \\
\hline Inferior vena cava filter use & $720(24 \%)$ & $206(24 \%)$ & $323(22 \%)$ & $191(27 \%)$ & 0.003 \\
\hline Ventilator support & $92(3.0 \%)$ & $33(3.9 \%)$ & $49(3.3 \%)$ & $10(1.4 \%)$ & 0.02 \\
\hline Percutaneous cardiopulmonary support & $39(1.3 \%)$ & $20(2.3 \%)$ & $18(1.2 \%)$ & $1(0.1 \%)$ & $<0.001$ \\
\hline \multicolumn{6}{|l|}{ Concomitant medications at discharge } \\
\hline Corticosteroids & $347(11.5 \%)$ & $68(8.0 \%)$ & $170(11.5 \%)$ & $109(15.7 \%)$ & $<0.001$ \\
\hline Non-steroidal anti-inflammatory drugs & $297(9.8 \%)$ & $90(10.5 \%)$ & $96(6.5 \%)$ & $111(16.0 \%)$ & $<0.001$ \\
\hline Proton pump inhibitors $/ \mathrm{H}_{2}$-blockers & $1,336(44 \%)$ & $370(43 \%)$ & $653(44 \%)$ & $313(45 \%)$ & 0.78 \\
\hline Statins & $437(14.4 \%)$ & $124(14.5 \%)$ & $259(17.5 \%)$ & $54(7.8 \%)$ & $<0.001$ \\
\hline Antiplatelet agents & $307(10.1 \%)$ & $95(11.1 \%)$ & $169(11.4 \%)$ & $43(6.2 \%)$ & $<0.001$ \\
\hline
\end{tabular}

Categorical variables are presented as numbers and percentages. Continuous variables are presented as the mean and standard deviation or the median and interquartile range based on their distributions. Categorical variables were compared with the chi-square test. Continuous variables were compared using one-way analysis of variance or Kruskal-Wallis test based on their distributions. Chronic kidney disease was diagnosed if there was persistent proteinuria or if eGFR was $<60 \mathrm{~mL} / \mathrm{min} / 1.73 \mathrm{~m}^{2}$ for $>3$ months. Chronic lung disease was defined as persistent lung disorders such as asthma, chronic obstructive pulmonary disease, and restrictive lung diseases. Previous heart failure was diagnosed if the patient had a history of hospitalization for heart failure, if the patient had symptoms related to heart failure (New York Heart Association functional class $\geq 2$ ), or if the left ventricular ejection fraction was $<40 \%$. Previous major bleeding was diagnosed if the patient had a history of International Society of Thrombosis and Hemostasis major bleeding, which consisted of a reduction in the hemoglobin level by at least $2 \mathrm{~g} / \mathrm{dL}$, transfusion of at least 2 units of blood or symptomatic bleeding in a critical area or organ. The detailed definitions of other patient characteristics are described in Appendix S2. DVT, deep vein thrombosis; eGFR, estimated glomerular filtration rate; MI, myocardial infarction; PE, pulmonary embolism; VTE, venous thromboembolism.

\begin{tabular}{|c|c|c|c|c|c|}
\hline & $\begin{array}{c}\text { Total } \\
(n=3,027)\end{array}$ & $\begin{array}{l}\text { Transient risk } \\
(\mathrm{n}=855)\end{array}$ & $\begin{array}{l}\text { Unprovoked } \\
(n=1,477)\end{array}$ & $\begin{array}{l}\text { Cancer } \\
(\mathrm{n}=695)\end{array}$ & $P$ value \\
\hline $\begin{array}{l}\text { Anticoagulation therapy beyond the } \\
\text { acute phase }\end{array}$ & $2,803(93 \%)$ & $789(92 \%)$ & $1,400(95 \%)$ & $614(88 \%)$ & $<0.001$ \\
\hline Warfarin & $2,676(88 \%)$ & $739(86 \%)$ & $1,361(92 \%)$ & $576(83 \%)$ & \\
\hline Direct oral anticoagulant & $78(2.6 \%)$ & $27(3.2 \%)$ & $31(2.1 \%)$ & $20(2.9 \%)$ & $<0.001$ \\
\hline Unfractionated heparin & $49(1.6 \%)$ & $23(2.7 \%)$ & $8(0.5 \%)$ & $18(2.6 \%)$ & \\
\hline TTR for INR 1.5-2.5 (\%) $(\mathrm{n}=2,509)$ & $72.3(45.5-91.5)$ & $74.5(49.1-93.6)$ & $75.7(50.2-93.0)$ & $60.7(36.8-81.3)$ & $<0.001$ \\
\hline TTR for INR 2.0-3.0 (\%) $(n=2,509)$ & $30.8(8.2-56.2)$ & $25.8(3.3-52.9)$ & $33.4(9.8-59.6)$ & $30.9(11.6-50.6)$ & $<0.001$ \\
\hline $\begin{array}{l}\text { Discontinuation of anticoagulation } \\
\text { during follow-up }\end{array}$ & $1,089 / 2,803(39 \%)$ & $366 / 789(46 \%)$ & $457 / 1,400(33 \%)$ & $266 / 614(43 \%)$ & $<0.001$ \\
\hline \multicolumn{6}{|l|}{ Reason for discontinuation } \\
\hline Physician's judgment & $648 / 1,089(60 \%)$ & $285 / 366(78 \%)$ & $282 / 457(62 \%)$ & $81 / 266(30 \%)$ & \\
\hline Bleeding event & $201 / 1,089(18 \%)$ & $37 / 366(10 \%)$ & $78 / 457(17 \%)$ & $86 / 266(32 \%)$ & $<0.001$ \\
\hline Other & $240 / 1,089(22 \%)$ & $44 / 366(12 \%)$ & $97 / 457(21 \%)$ & 99/266 (37\%) & \\
\hline $\begin{array}{l}\text { Interruption of anticoagulation during } \\
\text { follow-up }\end{array}$ & $344 / 2,803(12 \%)$ & $85 / 789(11 \%)$ & $151 / 1,400(11 \%)$ & $108 / 614(18 \%)$ & $<0.001$ \\
\hline
\end{tabular}

Categorical variables are presented as numbers and percentages. Continuous variables are presented as the median and interquartile range. Categorical variables were compared with the chi-square test. Continuous variables were compared using Kruskal-Wallis test. TTR was calculated by the Rosendaal method, according to a therapeutic INR range of 1.5 to 2.5 , which is recommended in the Japanese guidelines, as well as a therapeutic INR range of 2.0 to 3.0, which is recommended in the Western guidelines. Discontinuation of anticoagulation was defined as withdrawal of anticoagulation therapy lasting $>14$ days for any reasons such as physicians' judgment in the absence of adverse events, bleeding event, drug side effect, and non-adherence of the patients. Interruption of anticoagulation was defined as temporary cessation of anticoagulation therapy with reinstitution within 14 days for any reasons including invasive procedure and bleeding events, etc. INR, international normalized ratio; TTR, time in therapeutic range; VTE, venous thromboembolism.

unprovoked: 9.3\% vs. cancer: $17.7 \%, \mathrm{P}<0.001$ ) (Figure 2). The cancer group had a significantly higher risk for recurrent VTE compared with the transient risk group (HR, $2.88 ; 95 \% \mathrm{CI}, 2.02-4.14, \mathrm{P}<0.001)$, and the unprovoked group had a neutral risk for recurrent VTE compared with the transient risk group (HR, 1.08; 95\% CI, 0.77-1.53, $\mathrm{P}=0.65$ ). The cumulative 5-year incidences of major bleeding and all-cause death were also highest in the cancer group (major bleeding: $9.0 \%$ vs. $9.4 \%$ vs. $26.6 \%, \mathrm{P}<0.001$; all-cause death: $17.4 \%$ vs. $15.3 \%$ vs. $73.1 \%, \mathrm{P}<0.001$ ) (Figure 2). The cancer group had a significantly higher risk for major bleeding and all-cause death compared with the transient risk group (major bleeding: HR, 2.77; 95\% CI, 2.03-3.79, $\mathrm{P}<0.001$ and all-cause death: HR, 7.48; 95\% CI, 6.12-9.21, 


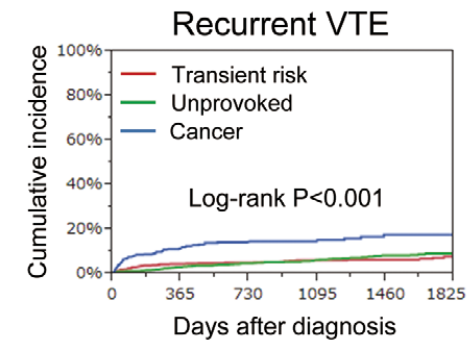

\begin{tabular}{|c|c|c|c|c|c|}
\hline & 0 -day & $\begin{array}{l}\text { 90- } \\
\text { day }\end{array}$ & 1-year & 3-year & 5 -year \\
\hline \multicolumn{6}{|l|}{ Transient risk } \\
\hline $\begin{array}{l}\mathrm{N} \text { of patients } \\
\text { with event }\end{array}$ & & 21 & 36 & 45 & 49 \\
\hline $\begin{array}{l}\mathrm{N} \text { of patients } \\
\text { at risk }\end{array}$ & 855 & 759 & 691 & 414 & 160 \\
\hline $\begin{array}{l}\text { Cumulative } \\
\text { incidence }\end{array}$ & & $2.6 \%$ & $4.6 \%$ & $6.1 \%$ & $7.9 \%$ \\
\hline \multicolumn{6}{|l|}{ Unprovoked } \\
\hline $\begin{array}{l}\mathrm{N} \text { of patients } \\
\text { with event }\end{array}$ & & 19 & 43 & 78 & 95 \\
\hline $\begin{array}{l}\mathrm{N} \text { of patients } \\
\text { at risk }\end{array}$ & 1477 & 1375 & 1269 & 770 & 279 \\
\hline $\begin{array}{l}\text { Cumulative } \\
\text { incidence }\end{array}$ & & $1.3 \%$ & $3.1 \%$ & $6.3 \%$ & $9.3 \%$ \\
\hline \multicolumn{6}{|l|}{ Cancer } \\
\hline $\begin{array}{l}\mathrm{N} \text { of patients } \\
\text { with event }\end{array}$ & & 48 & 65 & 75 & 78 \\
\hline $\begin{array}{l}\mathrm{N} \text { of patients } \\
\text { at risk }\end{array}$ & 695 & 496 & 311 & 144 & 42 \\
\hline $\begin{array}{l}\text { Cumulative } \\
\text { incidence }\end{array}$ & & $7.7 \%$ & $11.8 \%$ & $15.2 \%$ & $17.7 \%$ \\
\hline
\end{tabular}

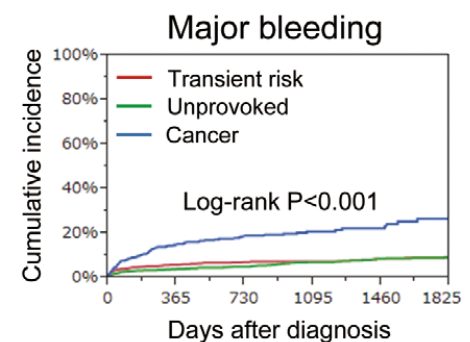

\begin{tabular}{|c|c|c|c|c|c|}
\hline & 0 -day & $\begin{array}{l}90- \\
\text { day }\end{array}$ & 1-year & 3-year & 5-year \\
\hline \multicolumn{6}{|l|}{ Transient risk } \\
\hline $\begin{array}{l}\mathrm{N} \text { of patients } \\
\text { with event }\end{array}$ & & 34 & 48 & 58 & 63 \\
\hline $\begin{array}{l}N \text { of patients } \\
\text { at risk }\end{array}$ & 855 & 751 & 687 & 413 & 159 \\
\hline $\begin{array}{l}\text { Cumulative } \\
\text { incidence }\end{array}$ & & $4.1 \%$ & $6.0 \%$ & $7.5 \%$ & $9.0 \%$ \\
\hline \multicolumn{6}{|l|}{ Unprovoked } \\
\hline $\begin{array}{l}\mathrm{N} \text { of patients } \\
\text { with event }\end{array}$ & & 42 & 57 & 91 & 103 \\
\hline $\begin{array}{l}\mathrm{N} \text { of patients } \\
\text { at risk }\end{array}$ & 1477 & 1351 & 1260 & 773 & 288 \\
\hline $\begin{array}{l}\text { Cumulative } \\
\text { incidence }\end{array}$ & & $2.9 \%$ & $4.0 \%$ & $7.2 \%$ & $9.4 \%$ \\
\hline \multicolumn{6}{|l|}{ Cancer } \\
\hline $\begin{array}{l}\mathrm{N} \text { of patients } \\
\text { with event }\end{array}$ & & 50 & 82 & 98 & 104 \\
\hline $\begin{array}{l}\mathrm{N} \text { of patients } \\
\text { at risk }\end{array}$ & 695 & 500 & 312 & 141 & 40 \\
\hline $\begin{array}{l}\text { Cumulative } \\
\text { incidence }\end{array}$ & & $7.9 \%$ & $15.3 \%$ & $21.0 \%$ & $26.6 \%$ \\
\hline
\end{tabular}

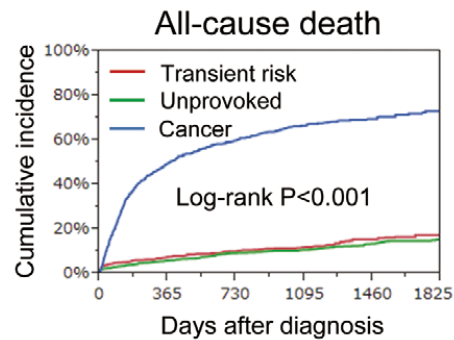

\begin{tabular}{|c|c|c|c|c|c|}
\hline & 0-day & $\begin{array}{l}90- \\
\text { day }\end{array}$ & 1-year & 3-year & 5-year \\
\hline \multicolumn{6}{|l|}{ Transient risk } \\
\hline $\begin{array}{l}\mathrm{N} \text { of patients } \\
\text { with event }\end{array}$ & & 43 & 63 & 92 & 113 \\
\hline $\begin{array}{l}\mathrm{N} \text { of patients } \\
\text { at risk }\end{array}$ & 855 & 784 & 734 & 441 & 175 \\
\hline $\begin{array}{l}\text { Cumulative } \\
\text { incidence }\end{array}$ & & $5.1 \%$ & $7.6 \%$ & $11.9 \%$ & $17.4 \%$ \\
\hline \multicolumn{6}{|l|}{ Unprovoked } \\
\hline $\begin{array}{l}\mathrm{N} \text { of patients } \\
\text { with event }\end{array}$ & & 47 & 86 & 145 & 175 \\
\hline $\begin{array}{l}\mathrm{N} \text { of patients } \\
\text { at risk }\end{array}$ & 1477 & 1392 & 1318 & 821 & 302 \\
\hline $\begin{array}{l}\text { Cumulative } \\
\text { incidence }\end{array}$ & & $3.2 \%$ & $6.0 \%$ & $10.7 \%$ & $15.3 \%$ \\
\hline \multicolumn{6}{|l|}{ Cancer } \\
\hline $\begin{array}{l}\mathrm{N} \text { of patients } \\
\text { with event }\end{array}$ & & 153 & 338 & 442 & 462 \\
\hline $\begin{array}{l}\mathrm{N} \text { of patients } \\
\text { at risk }\end{array}$ & 695 & 530 & 341 & 153 & 43 \\
\hline $\begin{array}{l}\text { Cumulative } \\
\text { incidence }\end{array}$ & & $22.3 \%$ & $49.6 \%$ & $66.6 \%$ & $73.1 \%$ \\
\hline
\end{tabular}

Figure 2. Kaplan-Meier curves for recurrent VTE, major bleeding, and all-cause death among the transient risk, unprovoked and cancer groups. VTE included PE and/or DVT. Abbreviations as in Figure 1.

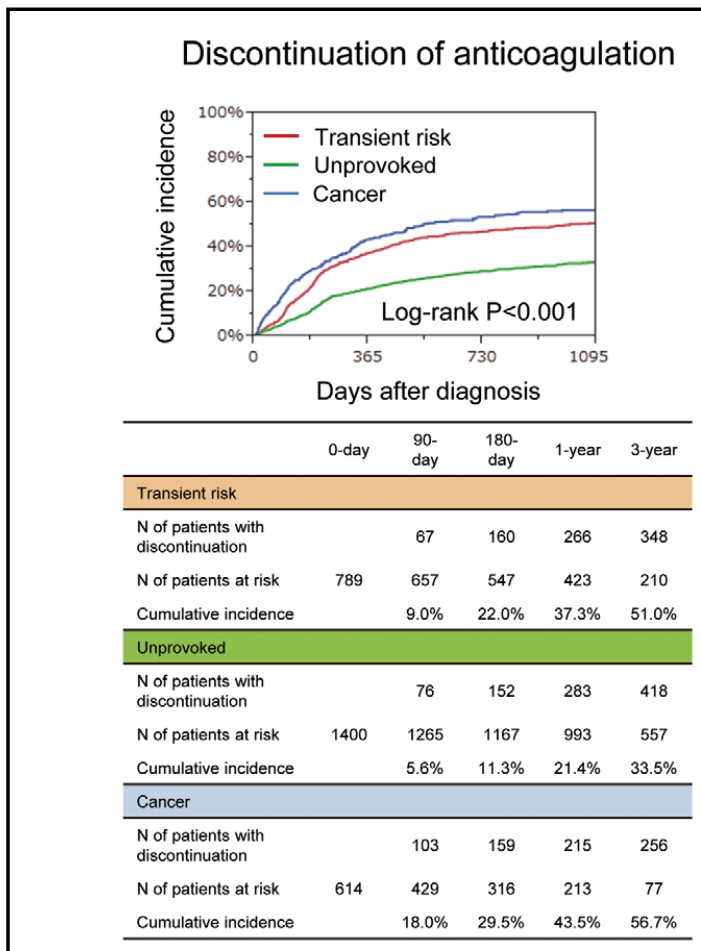

Figure 3. Kaplan-Meier curves for discontinuation of anticoagulation in patients who received anticoagulation therapy beyond the acute phase of venous thromboembolism.

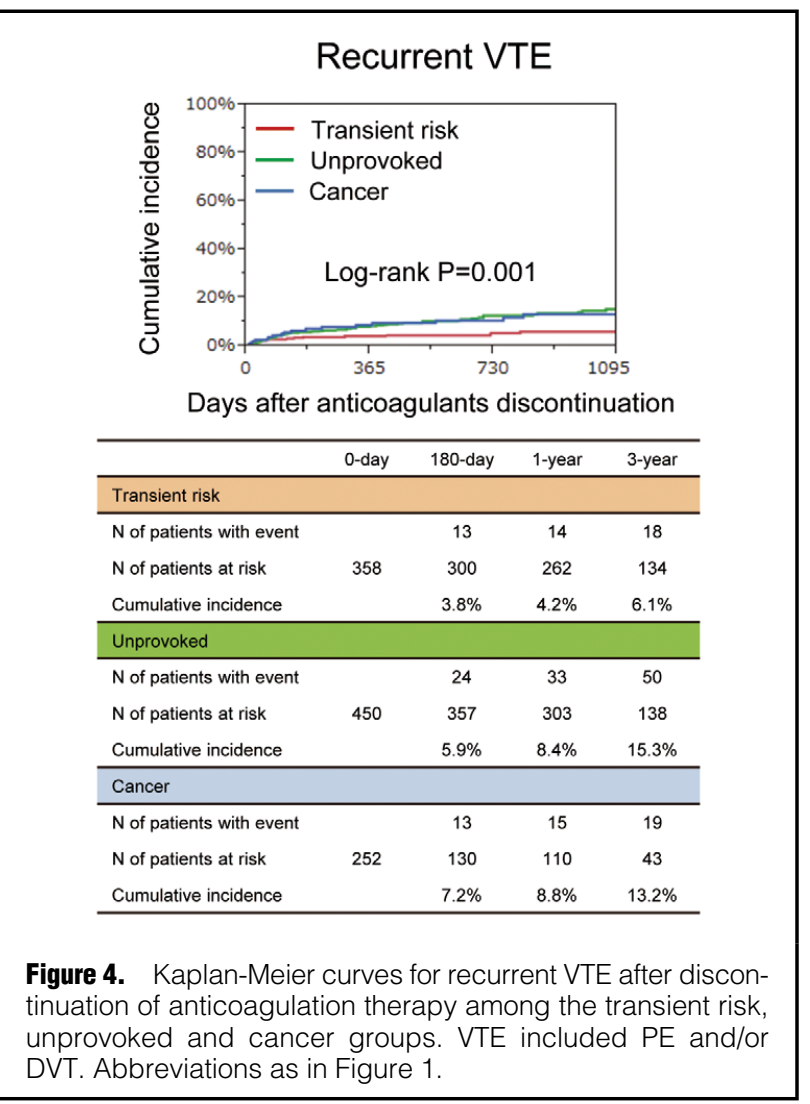




\section{Transient risk group}

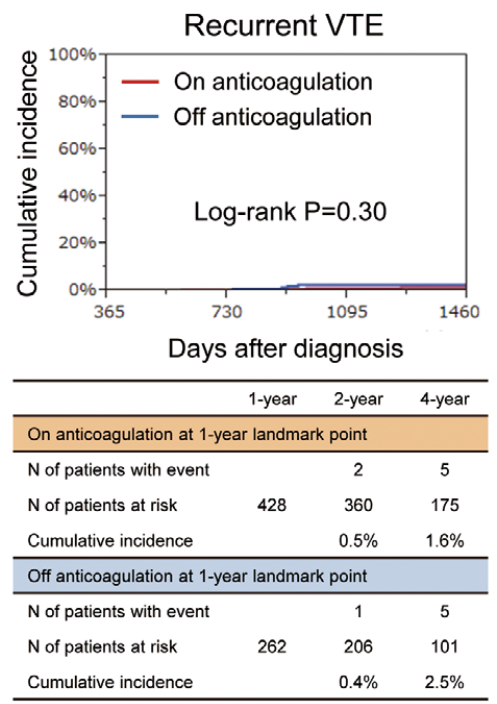

Unprovoked group

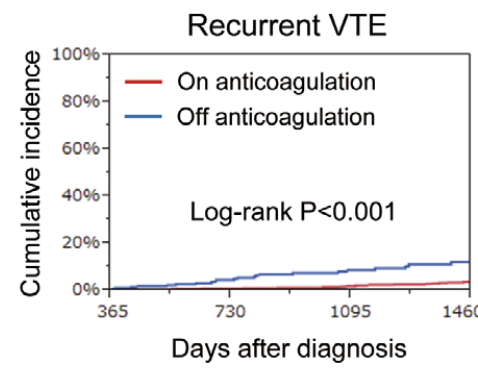

\begin{tabular}{lccc}
\hline & 1-year & 2-year & 4-year \\
\hline \multicolumn{4}{l}{ On anticoagulation at 1-year landmark point } \\
\hline $\mathrm{N}$ of patients with event & 9 & 25 \\
$\mathrm{~N}$ of patients at risk & 997 & 860 & 396 \\
Cumulative incidence & & $1.0 \%$ & $3.7 \%$ \\
\hline Off anticoagulation at 1-year landmark point \\
\hline $\mathrm{N}$ of patients with event & 11 & 23 \\
$\mathrm{~N}$ of patients at risk & 272 & 207 & 84 \\
Cumulative incidence & & $4.6 \%$ & $12.2 \%$ \\
\hline
\end{tabular}

Cancer group

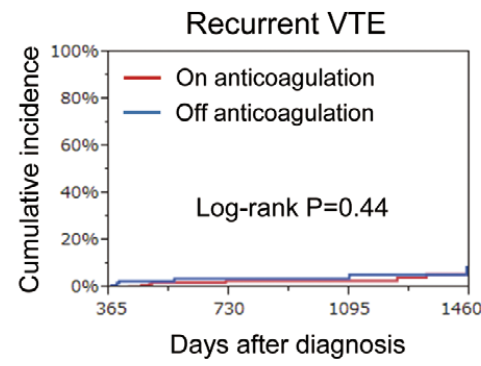

\begin{tabular}{lccc}
\hline & 1-year & 2-year & 4-year \\
\hline On anticoagulation at 1-year landmark point \\
\hline $\mathrm{N}$ of patients with event & 5 & 7 \\
$\mathrm{~N}$ of patients at risk & 199 & 148 & 53 \\
Cumulative incidence & & $2.9 \%$ & $5.6 \%$ \\
\hline Off anticoagulation at 1-year landmark point \\
\hline $\mathrm{N}$ of patients with event & 4 & 6 \\
$\mathrm{~N}$ of patients at risk & 111 & 83 & 30 \\
Cumulative incidence & & $3.8 \%$ & $8.6 \%$ \\
\hline
\end{tabular}

Figure 5. Kaplan-Meier curves for the landmark analysis on recurrent VTE beyond 1 year between the groups of patients on and off anticoagulation at the 1-year landmark point. VTE included PE and/or DVT. Abbreviations as in Figure 1.

$\mathrm{P}<0.001$ ), whereas the unprovoked group had a neutral risk for major bleeding and all-cause death compared with the transient risk group (major bleeding: HR, 0.86; $95 \%$ CI, 0.64-1.18, $\mathrm{P}=0.36$, and all-cause death: $\mathrm{HR}, 0.87 ; 95 \%$ CI, 0.69-1.10, $\mathrm{P}=0.23$ ). After taking into account the competing risk of all-cause death, the excess risk of the cancer group relative to the transient risk group for recurrent VTE and major bleeding remained significant, although the magnitude of risk was attenuated (Table S2). During the entire follow-up period, fatal PE (VTE-related death) occurred in 85 patients. Other clinical outcomes and the causes of deaths are shown in Table S3 and Table S4.

Among patients who received anticoagulation therapy beyond the acute phase, discontinuation of anticoagulation therapy was most frequent in the cancer group $(37.3 \%$ vs. $21.4 \%$ vs. $43.5 \%$ at 1 year, $\mathrm{P}<0.001$ ) (Figure 3 ). Discontinuation because of physician's judgment was most frequent in the transient risk group, and discontinuation because of a bleeding event was most frequent in the cancer group (Table 2). Interruption of anticoagulation during the entire follow-up period was also most frequent in the cancer group (Table 2).

\section{Effect of Prolonged Anticoagulation Therapy on Recurrent VTE}

After discontinuation of anticoagulation therapy, the cumulative 3-year incidence of recurrent VTE was lowest in the transient risk group (transient risk: 6.1\% vs. unprovoked: $15.3 \%$ vs. cancer: $13.2 \%, \mathrm{P}=0.001$ ) (Figure 4). The unprovoked group and the cancer group, respectively, had higher risk for recurrent VTE after discontinuation of anticoagulation therapy compared with the transient risk group (unprovoked: HR, 2.44; 95\% CI, 1.50-4.11, $\mathrm{P}<0.001$, and cancer: HR, 2.19; 95\% CI, 1.18-4.07, P=0.01). After taking into account the competing risk of all-cause death, the excess risk of the cancer group relative to the transient risk group for recurrent VTE was no longer significant (Table S2).

In the landmark analysis at 1 year, the cumulative 3-year incidence of recurrent VTE beyond 1 year was significantly lower in patients on anticoagulation at 1 year than in patients off anticoagulation at 1 year in the unprovoked group (on: $3.7 \%$ vs. off: $12.2 \%, \mathrm{P}<0.001$ ), but not in the transient risk or cancer group (transient risk: $1.6 \%$ vs. $2.5 \%$, $\mathrm{P}=0.30$, and cancer: $5.6 \%$ vs. $8.6 \%, \mathrm{P}=0.44$ ) (Figure 5).

\section{Discussion}

The main findings of the current study were as follows: (1) in VTE patients with a transient risk factor, longer-term anticoagulation therapy beyond 3 months was often implemented in discordance with the current guideline recommendations, and there was no difference in the cumulative incidence of recurrent VTE beyond 1 year regardless of the anticoagulation status at 1 year; (2) in unprovoked VTE patients or VTE patients with previous VTE, the prevalence of discontinuation of anticoagulation therapy gradually increased, and the risk for recurrent VTE beyond 1 year was significantly higher in patients off anticoagulation at 1 year than in patients on anticoagulation at 1 year; and (3) VTE patients with active cancer had a dismal prognosis, with higher rates of recurrent VTE, major bleeding and death than other types of VTE patients.

For decision-making on the duration of anticoagulation therapy, it is important to consider the risk of recurrent VTE after discontinuation of anticoagulation therapy. A previous systematic review evaluating recurrent VTE after discontinuation of anticoagulation therapy reported a lower rate $(3.3 \% /$ year) for provoked VTE compared with the rate for unprovoked VTE (7.4\%/year). ${ }^{21}$ Consistent with that previous report, the current study showed a lower rate of recurrent VTE after discontinuation of anti- 
coagulation therapy for the transient risk group (4.2\% at 1 year after discontinuation) compared with the rate for the unprovoked group ( $8.4 \%$ at 1 year after discontinuation). Considering the low rate of recurrent VTE after discontinuation of anticoagulation therapy, shorter-term anticoagulation therapy would be recommended for VTE patients with a transient risk factor. However, in the current study, the rate of discontinuation of anticoagulation therapy for VTE patients with a transient risk factor was relatively low ( $37.3 \%$ at 1 year), suggesting that physicians tended to be more concerned about the risk of recurrent VTE after discontinuation of anticoagulation therapy than the risk of bleeding with anticoagulation. Similarly, a report from the RIETE Registry reported a high prevalence of anticoagulation therapy beyond 1 year $(41.9 \%)$ in provoked VTE patients. ${ }^{22}$ Clinicians should note that the risk for recurrent VTE in patients with a transient risk factor is relatively low and long-term anticoagulation is associated with a known increased risk for bleeding.

The current guidelines recommend extended or indefinite anticoagulation therapy for patients without a transient risk factor or with previous VTE if they are low risk of bleeding. ${ }^{3-6}$ However, no clinical predictor of bleeding for VTE patients treated by anticoagulation therapy has been adequately validated. ${ }^{23}$ Also, several clinical predictors of recurrent VTE for unprovoked VTE patients have been developed to identify patients who can safely cease anticoagulation therapy, although they are not adequately validated and are not often implemented in current daily clinical practice. ${ }^{\mathbf{2 4}-26}$ Thus, there is still no general agreement on how long those patients need to receive anticoagulation therapy. A previous randomized clinical trial for unprovoked DVT reported that the clinical benefit associated with extending the duration of anticoagulation therapy to 1 year is not maintained after discontinuation of anticoagulation therapy. ${ }^{27}$ The current study showed that anticoagulation therapy was gradually discontinued for unprovoked VTE patients over time, and more than half of the reasons for discontinuation were the physician's judgment in the absence of adverse events. The risk of recurrent VTE beyond 1 year was considerably lower in patients on anticoagulation than that in patients off anticoagulation at 1 year, suggesting the potential benefit of extended anticoagulation therapy beyond 1 year in patients with unprovoked VTE.

Active cancer is a strong risk factor for recurrent VTE, and current clinical guidelines recommend indefinite anticoagulation therapy for active cancer patients with a low risk of bleeding, although the prognosis of VTE patients with active cancer has not been adequately studied yet. ${ }^{3-6}$ Unexpectedly, the current study showed that anticoagulation therapy was discontinued most frequently in active cancer patients, despite a high risk of recurrent VTE, partly because active cancer patients are generally considered to be at high risk for bleeding from the tumor, surgical procedure, and cancer-related thrombocytopenia. ${ }^{28}$ Actually, the current study showed the highest rate of major bleeding in active cancer patients and discontinuation because of a bleeding event accounted for nearly one-third of the discontinuation in active cancer patients. Furthermore, the current study also showed extremely high rates of death (49.6\% at 1 year). Consistent with the current study, a study reported that the median survival time of cancer patients with VTE was only 5.2 months for DVT and 3.0 months for PE, suggesting that cancer patients have an extremely high mortality rate if they are complicated with VTE. ${ }^{29}$ There was no difference in the incidence of recurrent VTE between patients on and off anticoagulation at 1 year among patients with active cancer, which might be contrary to the general expectation. The most likely explanation for this result might be that a certain proportion of active cancer patients beyond 1 year could be under good control in terms of cancer status with a reduced risk of recurrent VTE. For the decision-making on the duration of anticoagulation therapy in active cancer patients therefore, it might be important to consider not only the bleeding and mortality risk, but also the risk of recurrent VTE based on the cancer status of the individual patient.

\section{Study Limitations}

First, this was a retrospective cohort study with the limitations inherent to observational study design. The decisions regarding the intensity and duration of anticoagulation therapy beyond the acute phase were left to the discretion of the attending physicians. Second, demographics, practice patterns as well as clinical outcomes in patients with VTE in Japan may be different from those outside Japan. In particular, the difference in the prevalence of thrombophilia could have a certain influence on clinical outcomes. There are few patients with homozygous factor $\mathrm{V}$ Leiden or homozygous prothrombin G20210A among Asians, but both conditions are more common in Caucasians. ${ }^{30}$ Third, because the use of low-molecular-weight heparin for VTE was not covered by Japanese national insurance, warfarin was mostly used as the anticoagulation therapy beyond the acute phase for patients with active cancer, although lowmolecular-weight heparin is recommended over warfarin in the Western guidelines. ${ }^{3-5}$ Fourth, the recommended target INR for VTE in the Japanese guidelines is 2.0 (range, 1.5-2.5), which is lower than the target value (INR, 2.5; range, 2.0-3.0) used in other Western countries. The lower target INR had some influence on clinical outcomes. Finally, the cancer status was not evaluated after the index VTE event, and we could not assess the influence of the course of cancer on clinical outcomes.

\section{Conclusions}

In real-world VTE patients, the duration of anticoagulation therapy varied widely, in discordance with current guideline recommendations. Optimal duration of anticoagulation therapy should be defined according to the risk of recurrent VTE and bleeding as well as of death.

\section{Acknowledgments}

We appreciate the support and collaboration of the co-investigators participating in the COMMAND VTE Registry. We are indebted to the independent clinical research organization (Research Institute for Production Development, Kyoto, Japan) for technical support.

\section{Conflicts of Interest}

Y.Y. received lecture fees from Daiichi-Sankyo and Bristol-Myers Squibb. T. Morimoto received lecture fees from Mitsubishi Tanabe Pharma and Pfizer Japan and consultant fees from Asahi Kasei, Bristol-Myers Squibb, and Boston Scientific. M.A. received lecture fees from Pfizer, Bristol-Myers Squibb, Boehringer Ingelheim, Bayer Healthcare and Daiichi-Sankyo. T. Kimura serves as an advisory board member for Abbott Vascular and Terumo Company. All other authors have reported that they have no relationships relevant to the contents of this paper to disclose. 


\section{Funding}

The COMMAND VTE Registry is supported by an independent clinical research organization (Research Institute for Production Development, Kyoto, Japan) and research funding from Mitsubishi Tanabe Pharma Corporation. The research funder had no role in the design and conduct of the study, the collection, management, analysis, and interpretation of the data, or in the preparation, review, and approval of the manuscript.

\section{References}

1. Cohen AT, Agnelli G, Anderson FA, Arcelus JI, Bergqvist D, Brecht JG, et al. Venous thromboembolism (VTE) in Europe: The number of VTE events and associated morbidity and mortality. Thromb Haemost 2007; 98: 756-764.

2. Kyrle PA, Rosendaal FR, Eichinger S. Risk assessment for recurrent venous thrombosis. Lancet 2010; 376: 2032-2039.

3. Konstantinides SV, Torbicki A, Agnelli G, Danchin N, Fitzmaurice D, Galie N, et al. 2014 ESC guidelines on the diagnosis and management of acute pulmonary embolism. Eur Heart J 2014; 35: 3033-3069, 3069a-3069k.

4. Kearon C, Akl EA, Comerota AJ, Prandoni P, Bounameaux H, Goldhaber SZ, et al. Antithrombotic therapy for VTE disease: Antithrombotic Therapy and Prevention of Thrombosis, 9th ed: American College of Chest Physicians Evidence-Based Clinical Practice Guidelines. Chest 2012; 141: e419S-e494S.

5. Jaff MR, McMurtry MS, Archer SL, Cushman M, Goldenberg $\mathrm{N}$, Goldhaber SZ, et al. Management of massive and submassive pulmonary embolism, iliofemoral deep vein thrombosis, and chronic thromboembolic pulmonary hypertension: A scientific statement from the American Heart Association. Circulation 2011; 123: $1788-1830$.

6. JCS Joint Working Group. Guidelines for the diagnosis, treatment and prevention of pulmonary thromboembolism and deep vein thrombosis (JCS 2009): Digest version. Circ J 2011; 75: $1258-$ 1281.

7. Schulman S, Rhedin AS, Lindmarker P, Carlsson A, Larfars G, Nicol P, et al. A comparison of six weeks with six months of oral anticoagulant therapy after a first episode of venous thromboembolism: Duration of Anticoagulation Trial Study Group. $N$ Engl J Med 1995; 332: $1661-1665$.

8. Schulman S, Granqvist S, Holmstrom M, Carlsson A, Lindmarker P, Nicol P, et al. The duration of oral anticoagulant therapy after a second episode of venous thromboembolism: The Duration of Anticoagulation Trial Study Group. $N$ Engl J Med 1997; 336: 393-398.

9. Ridker PM, Goldhaber SZ, Danielson E, Rosenberg Y, Eby CS, Deitcher SR, et al. Long-term, low-intensity warfarin therapy for the prevention of recurrent venous thromboembolism. $N$ Engl $J$ Med 2003; 348: 1425-1434.

10. Monreal M, Suarez C, Fajardo JA, Barba R, Uresandi F, Valle $\mathrm{R}$, et al. Management of patients with acute venous thromboembolism: Findings from the RIETE registry. Pathophysiol Haemost Thromb 2003; 33: 330-334.

11. Nakamura M, Miyata T, Ozeki Y, Takayama M, Komori K, Yamada N, et al. Current venous thromboembolism management and outcomes in Japan. Circ J 2014; 78: 708-717.

12. Goldhaber SZ, Visani L, De Rosa M. Acute pulmonary embolism: Clinical outcomes in the International Cooperative Pulmonary Embolism Registry (ICOPER). Lancet 1999; 353: 1386-1389.

13. Pollack CV, Schreiber D, Goldhaber SZ, Slattery D, Fanikos J, O'Neil BJ, et al. Clinical characteristics, management, and outcomes of patients diagnosed with acute pulmonary embolism in the emergency department: Initial report of EMPEROR (Multicenter Emergency Medicine Pulmonary Embolism in the Real World Registry). J Am Coll Cardiol 2011; 57: 700-706.

14. Meissner MH, Moneta G, Burnand K, Gloviczki P, Lohr JM, Lurie $\mathrm{F}$, et al. The hemodynamics and diagnosis of venous disease. J Vasc Surg 2007; 46(Suppl S): 4S-24S.

15. Laporte S, Mismetti P, Decousus H, Uresandi F, Otero R, Lobo $\mathrm{JL}$, et al. Clinical predictors for fatal pulmonary embolism in 15,520 patients with venous thromboembolism: Findings from the Registro Informatizado de la Enfermedad TromboEmbolica venosa (RIETE) Registry. Circulation 2008; 117: 1711-1716.

16. Buller HR, Decousus H, Grosso MA, Mercuri M, Middeldorp
S, Prins MH, et al. Edoxaban versus warfarin for the treatment of symptomatic venous thromboembolism. $N$ Engl J Med 2013; 369: $1406-1415$.

17. Schulman S, Kearon C. Definition of major bleeding in clinical investigations of antihemostatic medicinal products in nonsurgical patients. J Thromb Haemost 2005; 3: 692-694.

18. Faller N, Limacher A, Mean M, Righini M, Aschwanden M, Beer JH, et al. Predictors and causes of long-term mortality in elderly patients with acute venous thromboembolism: A prospective cohort study. Am J Med 2017; 130: 198-206.

19. Rosendaal FR, Cannegieter SC, van der Meer FJ, Briet E. A method to determine the optimal intensity of oral anticoagulant therapy. Thromb Haemost 1993; 69: 236-239.

20. Fine JP, Gray RJ. A proportional hazards model for the subdistribution of a competing risk. J Am Stat Assoc 1999; 94: 496509.

21. Iorio A, Kearon C, Filippucci E, Marcucci M, Macura A, Pengo $\mathrm{V}$, et al. Risk of recurrence after a first episode of symptomatic venous thromboembolism provoked by a transient risk factor: A systematic review. Arch Intern Med 2010; 170: 1710-1716.

22. Ageno W, Samperiz A, Caballero R, Dentali F, Di Micco P, Prandoni $\mathrm{P}$, et al. Duration of anticoagulation after venous thromboembolism in real-world clinical practice. Thromb Res 2015; 135: 666-672.

23. Ruiz-Gimenez N, Suarez C, Gonzalez R, Nieto JA, Todoli JA, Samperiz AL, et al. Predictive variables for major bleeding events in patients presenting with documented acute venous thromboembolism: Findings from the RIETE Registry. Thromb Haemost 2008; 100: $26-31$.

24. Rodger MA, Kahn SR, Wells PS, Anderson DA, Chagnon I, Le $\mathrm{Gal} \mathrm{G}$, et al. Identifying unprovoked thromboembolism patients at low risk for recurrence who can discontinue anticoagulant therapy. CMAJ 2008; 179: 417-426.

25. Eichinger S, Heinze G, Jandeck LM, Kyrle PA. Risk assessment of recurrence in patients with unprovoked deep vein thrombosis or pulmonary embolism: The Vienna prediction model. Circulation 2010; 121: 1630-1636.

26. Tosetto A, Iorio A, Marcucci M, Baglin T, Cushman M, Eichinger S, et al. Predicting disease recurrence in patients with previous unprovoked venous thromboembolism: A proposed prediction score (DASH). J Thromb Haemost 2012; 10: 10191025.

27. Agnelli G, Prandoni P, Santamaria MG, Bagatella P, Iorio A, Bazzan M, et al. Three months versus one year of oral anticoagulant therapy for idiopathic deep venous thrombosis: Warfarin Optimal Duration Italian Trial Investigators. $N$ Engl J Med 2001; 345: $165-169$.

28. Kamphuisen PW, Beyer-Westendorf J. Bleeding complications during anticoagulant treatment in patients with cancer. Thromb Res 2014; 133(Suppl 2): S49-S55.

29. Joung S, Robinson B. Venous thromboembolism in cancer patients in Christchurch, 1995-1999. NZ Med J 2002; 115: 257 260.

30. Ridker PM, Miletich JP, Hennekens CH, Buring JE. Ethnic distribution of factor V Leiden in 4047 men and women: Implications for venous thromboembolism screening. JAMA 1997; 277: $1305-1307$.

\section{Supplementary File 1}

\section{Supplementary Files}

Appendix S1. List of Participating Centers and Investigators

Appendix S2. Definitions of patients' characteristics and clinical events

Appendix S3. Independent Clinical Event Committee

Table S1. Types of cancer in the cancer group

Table S2. HR and 95\% CI using a cox proportional hazard model with the competing risk of all-cause death

Table S3. Clinical outcomes during the entire follow-up period

Table S4. Causes of death during the entire follow-up period

Please find supplementary file(s);

http://dx.doi.org/10.1253/circj.CJ-17-1128 